\title{
Poder tutelar y formación del Estado en Brasil: notas a partir de la creación del Servicio de Protección a los Indios y Localización de Trabajadores Nacionales*
}

\author{
Antonio Carlos de Souza Lima
}

\begin{abstract}
El objetivo de este trabajo es presentar una crítica de la construcción narrativa acerca de la acción heroica del Estado republicano frente a pueblos indígenas en Brasil, centrada en la creación de una agencia del gobierno —el Servicio de Protección a los Indios en 1910 — por diversos actores sociales, donde sobresalen los militares positivistas. Esto se hace mostrando cómo la versión de "heroico", una auto-imagen del grupo creador de la agencia, pasó a verdad científica a través de la obra del antropólogo Darcy Ribeiro. El objetivo de este análisis es ofrecer elementos para la apertura de nuevas posibilidades interpretativas, incluso dando relevancia a la acción indigenista en muchas ocasiones.
\end{abstract}

PaLABRAS CLAVE: indigenismo, política indigenista, pueblos indígenas de Brasil, antropología brasileña, antropología de Estado

\begin{abstract}
Tutelage Power and the Formation of the State of Brazil: Notes from the Establishment of the Indian Protection and Localization of National Workers Service

The aim of this study is to depict a critique on the narrative construction about the republican State's heroic action towards the indigenous peoples of Brazil, centred on the creation of a governmental agency - the Servicio de Protección a los Indios (Indian Protection Service) in 1910- by diverse stakeholders, predominantly the positivist military members. This is accomplished by showing how the "heroic" version, a self-image of the group that created the agency, became a scientific truth through the work of anthropologist Darcy Ribeiro.The aim of this analysis is to offer elements for opening new interpretative possibilities, even often highlighting indigenist action.
\end{abstract}

KEYWORDS: indigenism, indigenist policies, indigenous peoples of Brazil, Brazilian anthropology, State's anthropology

\footnotetext{
Antonio Carlos de Souza Lima: Universidad Federal de Río de Janeiro, Río de Janeiro, Brasil acslima@gmail.com
}

\author{
Traducción: Clara I. Martínez Valenzuela \\ Desacatos, núm. 33, mayo-agosto 2010, pp. 53-66 \\ Recepción: 9 de marzo de 2009 / Aceptación: 23 de julio de 2009
}

\footnotetext{
* El presente texto es una reelaboración de parte de un capítulo de mi tesis de doctorado, defendida en 1992 en el pPGas/Museo Nacional, Universidad Federal de Río Janeiro, Río de Janeiro, Brasil. Parte de la tesis fue publicada en 1995 por la editorial Vozes (Souza Lima, 1995). Para la versión en español y su presentación hice algunas adaptaciones con el fin de que fuera legible para el público de habla hispana, alteraciones que no dan
} 
$\mathrm{E}$ 1 indigenismo y la política indigenista en Brasil tienen uno de sus momentos culminantes en 1910, cuando se funda la primera agencia del sistema de Estado instaurado con la República, cuyo objetivo era el establecimiento de relaciones de carácter puramente laico con los pueblos indígenas, en lo que atañe a sus cuadros y en lo que se refiere a su ideología. El Servicio de Protección a los Indios y Localización de Trabajadores Nacionales (SPILTN) pasó a la historia sólo como Servicio de Protección a los Indios (SPI) —en 1918, una reforma administrativa le quitó la atribución de localizar trabajadores nacionales - y a las páginas de los estudios antropológicos como creación personal y venerable del entonces teniente coronel Cândido Mariano da Silva Rondon, uno de los mitos incuestionables de la historia oficial del Brasil republicano, jefe del arma de Comunicación del Ejército Brasileño, de las Telecomunicaciones en general, primer brasileño postulado al Premio Nobel de la Paz (1958) y personaje central de numerosas biografías apologéticas ${ }^{1}$.

En el pasaje de esta narrativa del campo político al campo científico (división muy superficial en el Brasil de principios del siglo XX), otra figura fue, por lo menos, representativa de un complejo conjunto de relaciones e imbricaciones entre espacios sociales y trayectorias posi-

cuenta de numerosos trabajos surgidos después de la formulación inicial del trabajo y que, desde mi punto de vista, no alteran en nada los principales argumentos que aquí se presentan. Muchos de esos trabajos fueron beneficiarios de la investigación y de las elaboraciones aquí mostradas - lo reconozcan o no- de modo crítico o acatando los argumentos formulados a lo largo de una investigación que se remite a la maestría en Antropología Social (De Souza Lima, 1985, 1989 y 1991). Citarlos aquí sería como hacer una reseña cotejada de 25 años de trabajo sobre el indigenismo y la política indigenista en Brasil, lo que sustituiría el presente texto, sin duda hasta este momento inaccesible a los lectores mexicanos. Tal vez sea más importante señalar que, más allá de la esfera del indigenismo, el trabajo sirvió también de inspiración a estudios sobre antropología y política indigenista en otros contextos nacionales (Blanchette, 2006), minorías (Vianna, 2007 [1999]), y procesos de migración inducida (Morales, 2002; Ramos, 2006) entre la amplia gama temática que la investigación sobre el proceso de formación del Estado en Brasil ha recorrido.

${ }^{1}$ Sobre la creación del Servicio de Protección a los Indios y Localización de Trabajadores Nacionales, véase Souza Lima, 1985a, 1987 y 1995. Acerca del llamado Servicio de Poblamiento, que se encargaría de la parte relativa a los llamados trabajadores nacionales (campesinos pobres y negros liberados en 1888 con la abolición de la esclavitud), véase Ramos, 2006. Para un acercamiento a las construcciones en torno a la trayectoria de Cândido Rondon, véase Souza Lima, 1991. bles en la antropología brasileña, y probablemente también en la latinoamericana. Me refiero a Darcy Ribeiro, cuya carrera como etnógrafo inicia en 1947, precisamente en el $\mathrm{SPI}^{2}$.

\section{LA HISTORIA OFICIAL DE LAS AGENCIAS INDIGENISTAS DEL ESTADO BRASILEÑO}

Hasta mediados de la década de 1980, buscar referencias históricas de la actuación del Estado brasileño sobre los pueblos indígenas era encontrarse, inexorablemente, con un único texto clave: Os Índios e a Civilização, el célebre libro de Darcy Ribeiro publicado por primera vez en 1970 —durante el exilio del autor — por la "editorial de izquierda" Civilização Brasileira [citado aquí en su segunda edición (1977)], especialmente con la segunda parte de esta obra ${ }^{3}$.

En este texto, Ribeiro oponía la "ineficacia" de las "misiones religiosas" y las supuestas sugerencias de "exterminio" de los indios, a los intentos, precarios pero honrosos, de una

\footnotetext{
${ }^{2}$ Numerosos trabajos se han escrito sobre el trabajo de Darcy Ribeiro y probablemente muchos otros lo serán. Una breve consulta en las bases de datos de disertaciones y tesis en Brasil mostrará toda una gama de estudios acerca de la obra de este autor: desde su trayectoria como intelectual hasta su actuación política, pasando por los estudios de los textos literarios que produjo, reflejando con ello la riqueza y complejidad de su producción. Es importante mencionar que me basé ampliamente en el análisis de Mariza Peirano (1981) para elaborar parte de lo que critiqué cuando analicé por primera vez el papel de Ribeiro en la (no) construcción de una historia del indigenismo en Brasil. Textos como los de Mendes (2006) y Mattos (2007) abordan más densamente aspectos relativos a la adscripción de Ribeiro al Servicio de Protección a los Indios (más el primero que el segundo), contribuyendo así al avance del conocimiento de la trayectoria de este actor/autor. Es importante destacar, sin embargo, que parte de las cuestiones aquí abordadas señalan la supresión sistemática, a lo largo de varias décadas, de investigaciones empíricas más profundas sobre la historia del indigenismo y de la política indigenista en Brasil. Ésa es mi preocupación hasta hoy, más que las trayectorias de Ribeiro o de Rondon. Actualmente, cuando hay leyes que incitan al establishment de la educación nacional a incorporar al estudio de la historia la presencia indígena en el país, esa ausencia de trabajos que permitan la generación de síntesis didácticas se hace más evidente. Sobre un intento para superar tales limitaciones, véase Pacheco de Oliveira y Freire, 2006.

${ }^{3}$ Os Índios e a Civilização terminó por convertirse en un libro de referencia obligada para el estudio de los problemas indígenas en Brasil, con amplia difusión en diversos países, entre ellos México, donde la editorial Siglo XXI lo editó seis veces en el periodo que va de 1971 a 1985.
} 


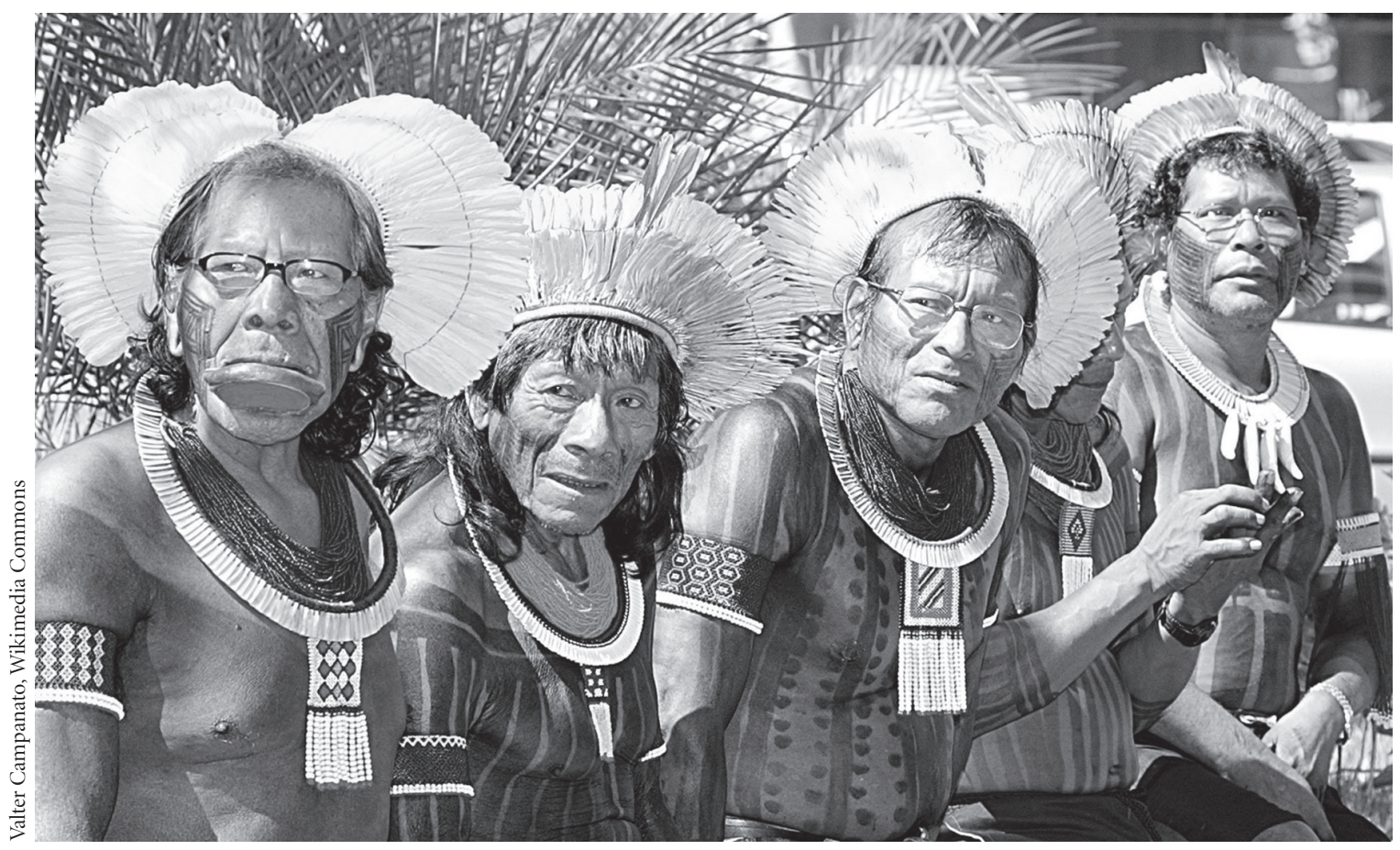

Caciques kaiapos durante una entrevista colectiva en Brasilia, 2005.

entidad del Estado brasileño creada expresamente para proteger y defender a los nativos. Mejor dicho, a pesar de señalar algunos límites del SPI, el texto contiene una defensa incisiva de la llamada protección fraternal y de la tutela, es decir, del mantenimiento - como dispositivo supuestamente positivo- del instituto jurídico de la incapacidad civil relativa de los indios establecida por el artículo sexto del Código Civil Brasileño, en vigor desde enero de 1917. De acuerdo con la Ley 5484/1928, que por primera vez regula la situación jurídica de los nativos bajo el régimen republicano, el Estado brasileño tendría bajo $t u$ tela a los pueblos indígenas, configurándose un régimen que, por otro lado, no podría ser equiparado con la anterior tutela ejercida sobre los indios por parte de los jueces de huérfanos. La Ley 5484/1928 le confiere al indio un estatus jurídico, aunque sin definirlo (esta tarea fue dejada a que se resolviese en lo cotidiano de la administración).

Ribeiro presenta al SPI (aunque la menciona, no le concede mucha importancia a la función original de localización de los trabajadores nacionales) como iniciativa casi personal de Cândido Mariano da Silva Rondon (el "héroe" de esta historia) y de un grupo de diligentes compañeros, reclutados ya sea entre los militares miembros de la llamada Comisión Rondon —Comisión de Líneas Telegráficas y Estratégicas de Mato Grosso a Amazonas (CLTEMGA) - o entre los ingenieros. Todos ellos estaban unidos en torno al credo positivista ortodoxo, al cual habían llegado a través de sus respectivas formaciones en la Escuela Militar de Praia Vermelha (donde hoy se ubica la Escuela Superior de Guerra, en Río de Janeiro) y en la Escuela Politécnica (más tarde Escuela Nacional de Ingeniería, actualmente Facultad de Ingeniería de la Universidad Federal de Río de Janeiro). En ambas instituciones el positivismo era moneda corriente, aunque bajo interpretaciones diversas.

Caricaturizando un poco el texto, se puede decir que Ribeiro nos relata una alegoría de abnegación y sufrimiento de algunos individuos excepcionales, enfrentados a las intemperies políticas, a la escasez de recursos, a la selva inhóspita y a los propios indios, muchas veces en guerra. 
Tal grupo, aunque dotado de una ideología equivocada para la época de Darcy Ribeiro, habría, según él mismo, conseguido enormes logros en las primeras décadas del siglo XX. Los herederos de este grupo serían precisamente quienes se ocuparon de reformar el SPI en el periodo que va de finales de la década de 1940 a principios de la de 1950 .

El discurso de Ribeiro hace énfasis en los años de la gestión de José Maria da Gama Malcher, quien trató de imprimir al SPI una dirección científica, favoreciendo principalmente a los etnólogos. Fue en este periodo cuando Darcy Ribeiro se convirtió en el etnólogo del SPI, en donde prestó sus servicios de 1947 a 1957, de tal forma que buena parte de su producción propiamente etnológica la hizo adscrito a esta institución. Ribeiro tuvo un papel destacado en la adopción de la antropología culturalista, muy en boga en la época, que sirvió como referente para la actuación del SPI y sustituyó a las ideas positivistas de incorporación de los indios, pocos años antes de que la institución cayera en manos de sucesivas gestiones corruptas ${ }^{4}$.

Poco después, el SPI se vio envuelto en el juego partidista del momento y decayó paulatinamente hasta los escándalos de la década de 1960, que culminaron con su desmantelamiento en 1967, dando paso a la creación de la Fundación Nacional del Indio (Funai), de acuerdo con la Ley $5.371 / 5-12-1967^{5}$.

\footnotetext{
${ }^{4}$ José Maria da Gama Malcher fue uno de los primeros funcionarios del SPI admitidos por medio de concurso público durante la década de 1940. Nacido en el estado amazónico de Pará, donde ocupó sus primeros cargos, siempre fue considerado un parámetro de honestidad, dedicación y percepción de nuevas posibilidades en lo referente a la protección de los indígenas brasileños, insertándose al mismo tiempo como continuador e innovador del "legado rondoniano". Durante su gestión como director de la entidad, entre 1950 y 1955, no sólo Darcy Ribeiro sino también el entonces recién formado y principiante Roberto Cardoso de Oliveira, y el primer antropólogo brasileño en obtener su doctorado en el extranjero, en la Universidad de Columbia, Eduardo Galvao, integran diferentes secciones, los dos primeros la Sección de Estudios y el tercero la Sección de Orientación y Asistencia del organismo. Véase los estudios de Freire (1990 y 2005); Souza Lima (1995 y 2006) y Mattos (2007) para un análisis de la trayectoria de Darcy Ribeiro. Véase Couto (2009) para la historia de la Sección de Estudios del SPI.

${ }^{5}$ Véase Souza Lima, 2001. Para una visión de las gestiones de la institución, véase $<\mathrm{http}$ ://pib.socioambiental.org/pt/c/politicas-indigenistas/o-estado/galeria-da-crise-permanente $>$ y el sitio oficial de la institución <http://www.funai.gov.br/index.html>, consultados el 19 de septiembre de 2009.
}

Una breve revisión de la producción etnológica brasileña entre 1970 y 1980 muestra que algunos autores que se referían a la política indigenista, aunque difirieran de Darcy Ribeiro en algunos aspectos, a veces incluso criticándolo fuertemente, reproducían su interpretación de la historia del surgimiento y de la práctica de la protección gubernamental a los pueblos indígenas. Sin negar la prominencia de grupos e individuos, si nos basamos en una sociología elemental de la producción intelectual y en la historia social, inevitablemente surge la pregunta de cómo un proceso social que alcanzó a amplios sectores del país, repercutiendo en la vida de indios y no indios, pudo surgir por la simple voluntad política de un grupo dotado de ideas humanitarias, más aún en un contexto de expansión económica sobre las tierras de pueblos que estaban en relativo resguardo de una penetración más intensa en sus territorios, lo que configuró conflictos exacerbados y violencias atroces.

¿Qué actores sociales, qué ideologías, que fuerzas políticas estaban entretejidas en la red de interdependencias necesaria para el surgimiento de una dependencia gubernamental?, ¿ cómo se pudo llegar —en un país donde los misioneros católicos fueron los agentes, por excelencia, de la actuación estatal entre los pueblos indígenas- a una morfología institucional liderada por ingenieros militares de formación positivista ortodoxa? Tales cuestiones parecen superfluas en la narrativa de Ribeiro, aunque en determinados momentos del texto él haya hecho críticas incisivas.

Aunque la intención de este texto no sea tratar a fondo la trayectoria de Darcy Ribeiro, es importante ubicar el momento en que hizo sus planteamientos. La primera edición del texto, que constituye la segunda parte de $O s$ Índios e a Civilização se titula A política indigenista brasileira, una publicación oficial del Ministerio de Agricultura al cual el SPI estaba burocráticamente vinculado. El texto de 1962 incluía una tercera parte que prácticamente fue desechada en el libro de 1970: era un proyecto de remodelación del SPI a partir de bases diferentes, acordes con los lineamientos que Ribeiro y otros intentaron implantar en la década de 1950. Ribeiro se encontraba en una posición privilegiada para proponer un nuevo modelo de acción indigenista oficial: era jefe de la Casa Civil 
bajo el gobierno de Goulart, en el turbulento periodo previo al golpe militar del 31 de marzo de 1964 que instauraría un régimen dictatorial en el país. En aquellos años, el SPI fue ferozmente atacado debido a numerosas denuncias de graves omisiones y por la participación de sus funcionarios en masacres de indígenas.

De hecho, el texto A política indigenista brasileira estaba prácticamente listo en informes que Darcy Ribeiro había escrito entre 1953 y 1954, como etnólogo de la Sección de Estudios del SPI, con el objetivo de defender a esta entidad de un proyecto de ley que proponía su desaparición y la lotificación de las tierras indígenas con base en un tortuoso criterio de "familia indígena". Al leer estos trabajos de Ribeiro - muy diferentes de la etnología ejercida por él en aquella década - se percibe que citaban informes de otros directores del SPI escritos en contextos semejantes, en una cadena cuyo inicio podría remontarse a 1910. Desde sus orígenes, el Servicio, como era llamado por sus primeros integrantes, había hecho una asociación totalmente desproporcionada: que proteger a los indios (es deber del Estado proteger a todos sus ciudadanos, compromiso que poco se ha cumplido, por cierto) era lo mismo que defender la existencia de una única dependencia gubernamental especialmente dedicada a tal tarea, confiriéndole a la idea de protección contenidos muy concretos: por protección se entendía tutela de Estado y esto implicaba una única agencia tutora. No obstante, ya había críticas en el momento en que Ribeiro luchaba en pro de los pueblos indígenas considerando que para ellos ésa era la mejor posición, cincuenta años después de la creación del SPI.

De hecho, en los primeros años de la década de 1960, etnólogos integrantes del Consejo Nacional de Protección a los Indios (creado en 1939 para orientar, en teoría, la acción del SPI) plantearon varios puntos de lo que debería ser una política indigenista científicamente orientada y liberada de una mayor presencia militar ${ }^{7}$. Esto podría explicar una serie de características que la primera gestión de la Funai (1967 a 1970) intentaría implantar en 1970,

\footnotetext{
${ }^{6}$ Véase Freire, 1990

${ }^{7}$ Idem.
}

bajo la responsabilidad del periodista José de Queiroz Campos. Después de este corto periodo, la institución volvió a estar bajo la fiscalización autoritaria de las esferas militares, volcadas en el control geopolítico del territorio nacional ${ }^{8}$.

Sin dejar de reconocer el valor de posturas ideológicas programáticas y teniendo claro lo instigador e innovador del texto de Ribeiro en el contexto de los años 1950-1960, lo que quiero subrayar es que fue preciso que pasaran algunas décadas para que se considerara la necesidad de una efectiva historia del indigenismo y de una reflexión basada en cánones científicos, no por esto menos políticos. Revisar tal posición implicaba, en la década de 1980, asumir otros lineamientos en lo que se refiere a la relación pueblos indígenas-Estado en Brasil, superando el predominio del segundo y su papel de tutor de los indígenas ${ }^{9}$. El hecho de que Ribeiro sea un antropólogo con reconocida e importante trayectoria como investigador no anula que en su intervención ante los pueblos indígenas encubrió, en 1970, el dato de que él jamás había investigado la estructura y la historia del SPI teniendo como finalidad la reconstrucción de las bases de la institución y la intención de repensarla. Lo que sí había hecho era una revisión histórica desde el punto de vista — bastante marcado, por cierto - de un participante interesado, un empleado del Servicio, buscando redimensionarlo en lo que tenía de negativo y en aquella coyuntura, realizando una defensa legítima de su existencia y de su papel como tutor de los pueblos indígenas. Desde esa óptica, era más una toma de posición en un juego político antes que produc-

\footnotetext{
${ }^{8}$ Para información básica de la gestión de José de Queiroz Campos, véase Souza Lima, 2001 y en línea $<$ http://pib.socioambiental.org/ $\mathrm{pt} / \mathrm{c} /$ politicas-indigenistas/o-estado/galeria-da-crise-permanente $>$, consultado por última vez el 19 de septiembre de 2009.

${ }^{9}$ El Código Civil Republicano, aprobado en 1916 y vigente hasta el año 2000, establecía: "Art. 6 Son incapaces, relativamente a ciertos actos (Art. 147, n. 1), o a la manera de ejercerlos: I. Los mayores de diez y seis y los menores de veintiún años (Arts. 154 a 156), II. Los pródigos, III. Los silvícolas. Párrafo único. "Los silvícolas quedarán sujetos al régimen tutelar, establecido en leyes y reglamentos especiales, lo cual cesará en la medida de que se fueran adaptando a la civilización del país". Para el Código como un todo, con todas las enmiendas que sufre, véase en línea: <http://www.dji.com.br/codigos/1916 lei_003071_cc/cc002a0012.htm>, consultado por última vez el 19 de septiembre de 2009
} 
ción de conocimiento (aunque una y otra se puedan sobreponer, pero siempre reconociendo que están regidas por cánones diferentes).

En cierto sentido, el texto de Ribeiro (1962) tenía el carácter de un libelo a favor de la permanencia del SPI, bajo una severa reforma y con una atención que los centros de poder decisorio en Brasil siempre negaron a los indígenas, salvo cuando se entrecruzaban el reconocimiento de los derechos de esos pueblos (en especial en el plano internacional) y la presión sobre sus tierras, fenómeno que se potencializó efectivamente después de la primera gran expansión estatal sobre la Amazonia, de la década de 1970 en adelante. Al formar parte de Os Índios e a Civilização - indiscutiblemente el primer (y hasta cierto punto todavía hoy único) trabajo de síntesis sociológica sobre varios aspectos de la relación entre pueblos indígenas y Estado nacional en Brasil—, el libelo institucional de 1962 asumió el rasgo de una historia crítica de la acción indigenista del SPI, tanto más en el contexto político de la dictadura militar y de su expansión sobre la región amazónica. Se ocultaba así lo que el texto tenía de historia
Tal situación no es privativa del SPI. También se da en muchas dependencias administrativas del sistema de Estado de Brasil, y los proyectos para redefinirlas son frecuentes. Es decir, ya sea bajo la forma escrita (en boletines, revistas, libros o registros sonoros o audiovisuales producidos al interior con criterios de verdad propios de la institución), o en forma oral, en un "folklore nativo" transmitido de los más antiguos empleados a los más nuevos, en ocasiones reguladas (reuniones, cursos, entrenamientos, etcétera) o cotidianas (conversaciones, intrigas, dentro y fuera del espacio de trabajo), las instituciones burocráticas se cuentan y recuentan. El modo escrito y el oral suelen complementarse y sobreponerse, reforzarse o desautorizarse, conforme a las posiciones dentro de las dependencias, pues aunque muchas veces la ideología de las agencias gubernamentales o no gubernamentales las retrate como entidades sin conflictos internos - "grandes familias"-, en realidad todas son virtualmente campos de disputa donde están en juego diversos intereses, y todas detentan constricciones jerárquicas que implican fricciones. En muchos casos, esas alegorías tienen que ver con demandas por presupuesto o por autonomía institucional, o también por el control monopólico de un conjunto de funciones.

Una investigación posterior acerca de la historia de la Fundación Nacional del Indio - breves apuntes bajo la forma de un artículo de diccionario- demostraría también la ausencia de estudios sobre la historia de la Funai; ni siquiera existe un relato de la trayectoria de la agen$\mathrm{cia}^{10}$. Los pocos que decían algo sobre ese tema, en aquel momento, reproducían un pequeño fragmento de la "Introducción” de Os Índios e a Civilização, en el que Ribeiro oponía los "buenos militares" de los tiempos de Rondon a los "nuevos militares" creadores de la Funai, los mismos que lo condujeron al exilio, momento previsto por él como el inicio de "tiempos todavía más adversos", pues con esto se estaría inaugurando una "nueva política de cuño empresarial"11.

Pocos trabajos debatían — sobre todo frente a las atrocidades infligidas a los pueblos indígenas en aras de una política de integración nacional como la concebida por el régimen militar vigente en Brasil de 1964 a 1984- si la Funai era heredera o no del SPI y de Rondon - figura mítica usada en muchas disputas a favor y en contra de las orientaciones militares- y si debía seguir tal o cual rumbo acorde con esa herencia ${ }^{12}$. Estos textos ayudan poco a entender las razones de su creación y su funcionamiento.

Si bien es cierto que a partir de 1980 hubo muchos trabajos que analizan aspectos de la trayectoria del SPI y otros sobre las actividades de la propia Funai, también es cierto

\footnotetext{
${ }^{10}$ Véase Souza Lima, 1985b y 2001 (versión revisada).

${ }^{11}$ Para esto, véase Ribeiro, 1977: 6. Es importante hacer notar que Rondon tuvo una importante actividad, jamás considerada por los exaltadores de su memoria como protector de los indios, en su condición de miembro del Ejército brasileño, incluso como comandante de expediciones en contra de grupos revoltosos de izquierda en las primeras décadas del siglo Xx. De hecho, estuvo poco tiempo al frente de la dirección del SPI, aunque su nombre figuró durante mucho tiempo.

12 Para un análisis de la elaboración de una autobiografía de Rondon (las cursivas son para subrayar la figura mítica y no al actor histórico concreto dotado de una trayectoria social), véase Souza Lima, 1991. No obstante, es importante señalar que en mi investigación sobre el indigenismo nunca me preocupé por de-construir la mitología rondoniana, siempre recontada e irreductible en Brasil. Mi preocupación fue más bien analizar las prácticas tutelares del Estado sobre los indígenas y el papel de las instituciones en esto.
} 


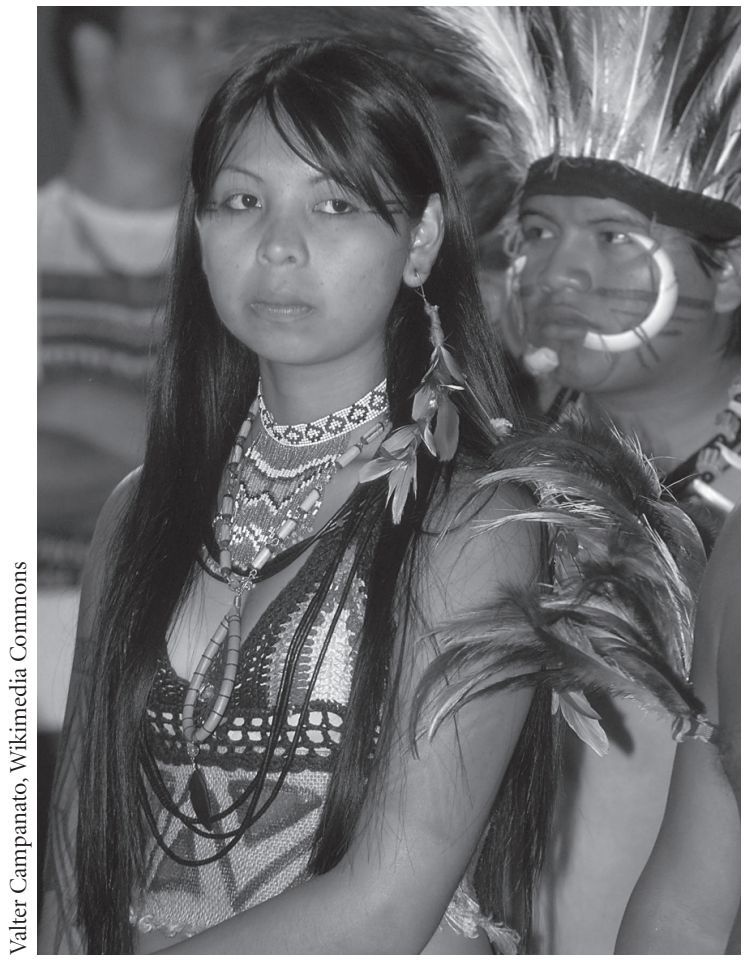

Indígena de la etnia terena en la ceremonia de clausura de los IX Juegos de los Pueblos Indígenas, 2007.

que un estudio de estas instituciones per se todavía está por hacerse. Así, se puede afirmar que la reproducción de una única versión del surgimiento de los poderes del Estado republicano frente a los indios (entendida esta designación como un estatus jurídico definido por la ley), la defensa del monopolio estatal de las acciones sobre los pueblos indígenas y el mantenimiento de su carácter $t u$ telar - y la propia lógica discursiva que estructura su pasado como en una especie de "edad de oro"— no están ni de lejos superadas ${ }^{13}$. En la actualidad, todavía hay posiciones que consideran que debemos venerar el pasado tutelar que, sin duda, tuvo muchos logros (como el propio Darcy Ribeiro lo mostró desde 1970) pero también muchas pérdidas.

\footnotetext{
${ }^{13}$ Un excelente ejemplo de esa continua defensa de ciertas posiciones que se fundamenta en la figura mítica más que en la presencia histórica de Cândido Mariano da Silva Rondon puede encontrarse en Gomes, 2009
}

Por lo tanto, era necesario tratar de entender cómo se construyeron los ejercicios tutelares, cómo se llegó a la creación del SPI, cuáles fueron sus objetivos, bajo qué coyuntura histórica surgió, cuáles fueron sus elementos componentes, qué códigos lo regían, cómo definía a su población-meta: los indios. A final de cuentas, bajo la Funai lo que más se discutió, durante la década de 1980, fue lo que se conoció como criterios de indianidad, es decir, criterios distintos de los planteados en la única ley destinada a regir la acción pública oficial referente a los nativos, y que contenía la idea de que eran indios aquellos que se reconocieran y fueran reconocidos por su comunidad de origen como tales. A pesar de que Brasil había firmado tanto la Convención 169 sobre Pueblos Indígenas y Tribales de la Organización Internacional del Trabajo como la Declaración de las Naciones Unidas sobre los Derechos de los Pueblos Indígenas, tales posiciones no desaparecieron, e incluso hay algunos indígenas, íntimamente vinculados con los mecanismos clientelistas del Estado, que las endosan ${ }^{14}$.

\section{ELEMENTOS PARA OTRA LECTURA}

Según la interpretación de Ribeiro, ampliamente basada en el trabajo del historiador estadounidense David Hall Stauffer, la creación del SPILTN viene del "debate" entre letrados y actores políticos efectuado entre 1908 y 1909 en torno al tratamiento, por parte del Estado republicano, de los pueblos indígenas, en especial frente a las numerosas zonas de conflicto en el Brasil de la época debido a la invasión de tierras indígenas. Tal debate tendría como posiciones polares la que defendía la catequesis misionera y la que estaba a favor del exterminio físico de los indígenas. Tal lectura redujo el conocimiento de dicha dependencia a un estudio de las representaciones de la época sobre los indios.

\footnotetext{
${ }^{14}$ El texto de la Convención 169 puede ser consultado en línea, en $<\mathrm{http}$ //www.planalto.gov.br/consea/Static/documentos/Eventos/III Conferencia/conv_169.pdf $>$. Para la Declaración de las Naciones Unidas sobre los Derechos de los Pueblos Indígenas, véase $<$ http:// www.un.org/esa/socdev/unpfi/documents/DRIPS_pt.pdf $>$, consultado por última vez el 19 de septiembre de 2009.
} 
Revertir este marco interpretativo implica rescatar aspectos poco abordados hasta la fecha en ese proceso de estatización. Un primer punto es la red que vinculó a Cândido Rondon y al Ministerio, es decir, cómo se produjo el acoplamiento entre la actuación del Estado sobre los indios —el diseño institucional establecido en 1910 a partir de actores vinculados a determinada posición política- $y$ los militares cuya tarea era reforzar el control gubernamental sobre el territorio y la población dispersa en él.

La idea de fundar una instancia para la catequesis y la civilización de los indios data de 1906, a partir del decreto que aprueba la creación del Ministerio de Agricultura, Industria y Comercio (MAIC), hecho reconocido por actores vinculados al SPI. Como meta administrativa, precede por mucho al "debate" catequesis versus exterminio, y es un elemento, entre otros, presente en la imaginación política como parte de la "discusión". Por otro lado, para la conciencia pública el nombre de Cândido Rondon se asocia a acciones heroicas frente a los indios, incluso antes de los hechos de 1908-1909. Asimismo, una serie de conferencias dictadas por Rondon en 1910, en Río de Janeiro y en São Paulo, tal vez haya reforzado su prestigio. En ellas, Cândido Rondon presentó a la nación el modo de vida de los pueblos indígenas y demostró que era posible "civilizarlos" por medio de la persuasión, sin el concurso de las armas, retomando un conjunto de técnicas de atracción y pacificación de pueblos hostiles acuñadas, en buena medida, por los misioneros jesuitas durante el periodo colonial.

Por otro lado, recuérdese que Cândido Rondon era un funcionario público (entre otros tantos), en este caso militar. Criticar la idea de un movimiento de la "opinión pública" a favor de la acción del Estado frente a los nativos, como explicación de la creación del SPILTN, permite elaborar de mejor manera el vínculo entre redes sociales estatizadas y la creación de la dependencia, dejando atrás el enfoque de posiciones en disputa en un supuesto campo de autonomización.

La idea de crear una agencia específica para tratar con los pueblos indígenas surgió cuando se presentó el supuesto debate catequesis versus exterminio en las representaciones publicadas en textos de actores del Museo Nacional, institución también integrada burocráticamen- te al MAIC y que ya mantenía relaciones bastante estrechas con la CLTEMGA. El vínculo entre Cândido Rondon, el Museo Nacional y los cuadros administrativos del MAIC se daba por diversos medios, especialmente por la presencia de Mario Barbosa Carneiro, positivista del Apostolado, primo de los hermanos Horta Barbosa — colaboradores de Rondon en la CLTEMGA y después en el SPI-, compadre de Rondon en el rito positivista, y director general de Contabilidad del MAIC durante el periodo que va de 1910 a $1930^{15}$.

Según información recogida de Paulo Carneiro — hijo de M. B. Carneiro— - por D. Stauffer y Lewis Hanke, fue Domingos Sergio de Carvalho quien invitó a Rondon a fundar el Servicio ${ }^{16}$. Carvalho, ingeniero agrónomo, fue director de la Sección de Antropología del Museo Nacional, secretario general y director para asuntos relacionados con el alcohol, y en 1910 consultor técnico del MAIC. El objetivo de la invitación fue proseguir con la implementación del Ministerio, siempre y cuando la retórica fuera la salvación científica de los silvícolas y no el supuesto genocidio de los indígenas ${ }^{17}$.

Los cambios en la relación Iglesia/Estado, aparte del inequívoco predominio de positivistas ligados al Apostolado Lego en las filas del SPILTN, fueron fundamentales para la separación de la idea de catequesis (entendida como el uso de miembros de órdenes religiosas en calidad de empleados de una dependencia del Estado para el trabajo directo con los pueblos indígenas). Lo sustituiría la presencia

\footnotetext{
15 "La Iglesia Positivista de Brasil [el Apostolado Lego], o Centro Positivista Brasileño, fue fundada por Miguel Lemos en Río de Janeiro en 1881, para designar a la totalidad de los positivistas de Brasil, con el objetivo de desarrollar el culto, organizar la enseñanza e intervenir oportunamente en los negocios públicos. Este último objetivo fue dejando de concretizarse en la medida en que el positivismo se afirmó como institución eclesiástica, cuya manifestación incluye cultos públicos y domésticos, misas, vestimenta especial, oraciones, cánticos, sacerdocio y sacramentos, en número de nueve (presentación, iniciación, admisión, destinación, matrimonio, madurez, retiro, transformación e incorporación). Su templo, idéntico al que existe en París, fue inaugurado en 1927 en Río de Janeiro". En línea en <http://www.cpdoc.fgv. br/accessus/docreader/ip_digital_consulta.htm $>$, consultado por última vez el 19 de septiembre de 2009. Sobre el papel fundamental del Apostolado en el cultivo de un espíritu republicano entre algunos segmentos de la elite brasileña, véase Carvalho, 1990, 1995.

${ }^{16}$ Sobre David Hall Stauffer y Lewis Hanke, véase Souza Lima, 1989.

17 Véase Stauffer, 1955: 271 y siguientes.
} 
militar y el uso instrumental del término protección, como un hecho consciente y parte de la lucha por la laicización de los servicios estatizados y de los recursos materiales que involucraban.

Los vínculos sociales entre el grupo rondoniano y el núcleo gubernamental que tomaba decisiones eran de hecho más extensos. En 1882, durante su formación militar, Cândido Rondon había sido amanuense de la secretaría del Segundo Regimiento de Artillería a Caballo, presentó sus servicios en la cuarta batería comandada en esa época por el capitán Hermes da Fonseca: misma compañía, y bajo el mismo comando, que fungió como vínculo entre la Marina y el Ejército en el episodio de la proclamación de la República ${ }^{18}$. En 1910, Hermes da Fonseca tomó el poder como presidente de la República, tras lo cual su relación con Cândido Rondon se hizo aún más fuerte. Fonseca defendió la continuidad de la Comisión Rondon (como se conocería a la CLTEMGA) contra la propuesta de disolución hecha por José Joaquim Seabra, entonces ministro de Transportes y Obras Públicas, titular de la cartera gubernamental a la que la Comisión estaba vinculada.

La red que condujo a la creación del SPI era, más ampliamente, la relacionada con la institucionalización del MAIC y con las ideas que secundarían su creación, bastante coherentes con el ideario positivista, desde el papel de la ciencia y las posibilidades de progreso para el campo bajo un gobierno racional, hasta las técnicas de manipulación imaginaria empleadas. En parte se sobreponía a la red involucrada de modo más directo en la campaña hermista, frente a la cual el cubrir cargos del Servicio y del Ministerio tuvo el carácter de trueque: un cargo político en el recién creado SPILTN era un elemento más de intercambio en la búsqueda de apoyo político en un país escindido en múltiples redes oligárquicas y dotado de una débil interdependencia entre redes regionales.

Con la instalación de un grupo de positivistas ortodoxos en el SPILTN se contemplaba —en el intercambio político de aquel momento- la idea de una agencia no gubernamental formadora de opinión, opuesta siempre a la participación de las Fuerzas Armadas en la vida política,

\footnotetext{
18 Véase Souza Lima, 1991: 64-65, y O’Reilly, 1969.
}

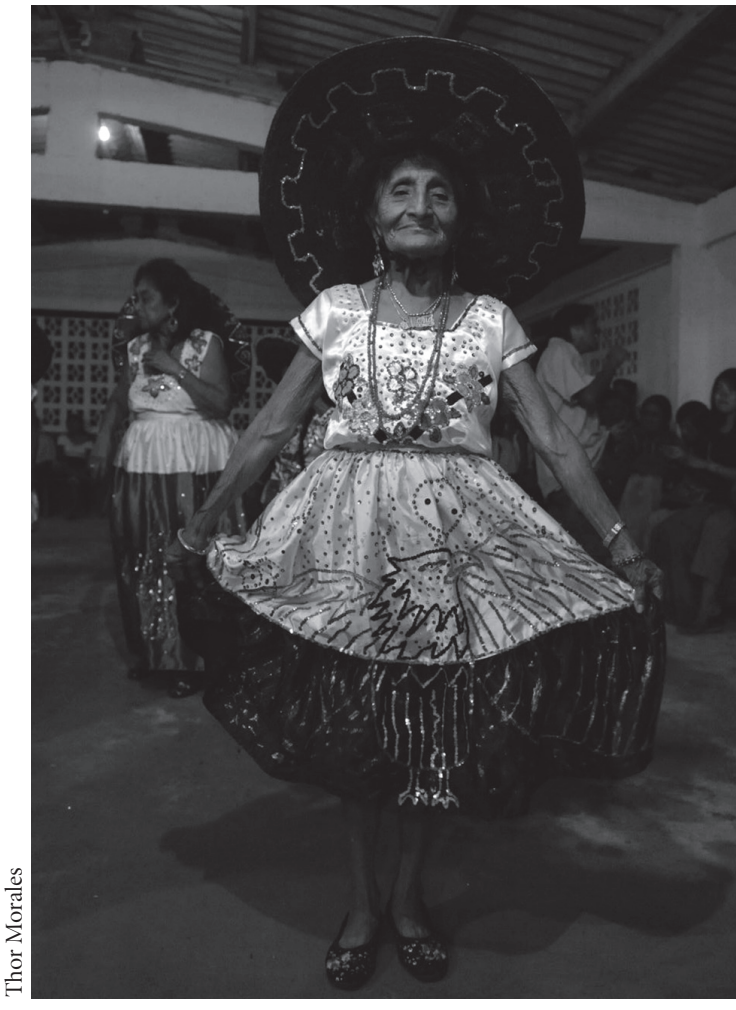

Mujer kuna representando bailes típicos mexicanos en honor de los invitados comcaac. Narganá, Kuna Yala, Panamá, 2009.

discusión delicada frente a la candidatura de Hermes da Fonseca. Para los ortodoxos, muy eclipsados en aquel periodo, las ventajas eran evidentes ya que se presentaba la posibilidad de comenzar por los pueblos indígenas (supuesta materia prima de la patria como la imaginaban) un trabajo "pedagógico" de (re)formación de Brasil, muy al gusto de sus propósitos. Y si ser presidente de la República era, evidentemente, ser actor político, en la visión positivista ortodoxa de la política ser director de una dependencia como el SPI era algo muy diferente: se servía a la patria al procurar construir a su pueblo. No en vano los textos influenciados o escritos por positivistas ortodoxos en los años posteriores a la creación del SPILTN, así como la campaña por la nacionalización del petróleo en la década de 1950, fueron invocados en calidad de momentos gloriosos en las representaciones positivistas de la trayectoria del Apostolado Lego. 


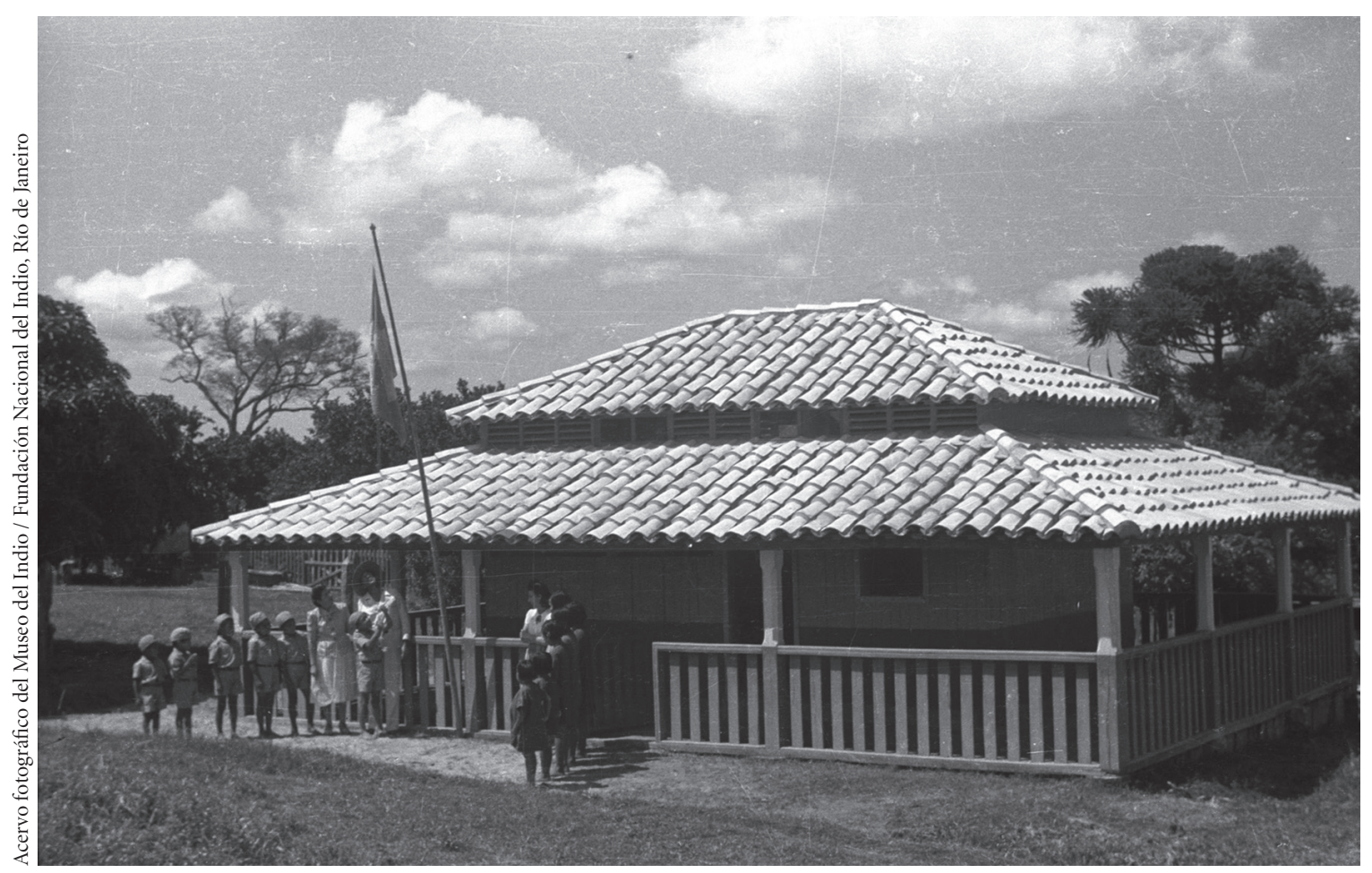

En 1910, la invitación de Rodolpho Miranda, ministro de Agricultura, Industria y Comercio, a Cândido Rondon para crear el SPILTN, y la respuesta de éste, ambas difundidas en la prensa de la época, deben entenderse como piezas clave de rituales que garantizarían el respeto a las ideas positivistas aplicadas previamente ${ }^{19}$. El ministro demostraría su intención de acatarlas satisfaciendo a determinados grupos. Rondon y Miranda representaban los ideales republicanos en un periodo en que los valores asociados a la monarquía tenían que ponerse al margen, entre ellos, la fuerte presencia eclesiástica en la vida pública. A final de cuentas, administrar una dependencia (el SPI) que casi siempre sería deficitaria, tanto en términos de presupuesto como de apoyo político, en un ministerio igualmente secundario y desprestigiado como fue el MAIC durante toda su existencia, parece haber sido en gran me-

\footnotetext{
${ }^{19}$ En lo que se refiere a la percepción de la dimensión ritual y escénica - teatral—de todo juego político, me basé en Geertz, 1991.
}

dida un teatro para el que los positivistas estaban especialmente preparados ${ }^{20}$.

La vasta producción escrita, las películas y conferencias a cargo de agentes directamente relacionados con el CLTEMGA y el SPILTN, además del apoyo de sus aliados, actuarían para construir las imágenes de valentía, altruismo, patriotismo y desinterés de los actores vinculados al trabajo de protección. Recuperar la representación elaborada por los cuadros del SPILTN sobre sí mismos es revisar la imagen del misionero en el periodo colonial (de los cuales los jesuitas José de Anchieta y Manuel da Lóbrega eran los paradigmas). El misionero fue el primer papel interpretado en la historia de las conquistas formadoras de Brasil, el trabajo de sublimación de la violencia desempeñado por la administración de la conquista frente a los pueblos nativos. Por otro lado, también es retomar las bases de construcción del poder tutelar, en el cual la violencia física se transforma en persuasión, en violencia

\footnotetext{
${ }^{20}$ Acerca de la trayectoria histórica del MAIC, véase Mendonça, 1997.
} 
simbólica, reeditando el imaginario colonial y las tradiciones que desembocan en el sertanismo ${ }^{21}$, la propia matriz de Brasil de las prácticas del poder sobre los indígenas, que más tarde se fundirían en lo que se conoció comúnmente como indigenismo.

\section{EL SPI COMO EJECUTOR DE LATUTELA DEL ESTADO SOBRE LOS INDÍGENAS}

El Servicio fue creado en junio de 1910, aunque sería inaugurado públicamente hasta el 7 de septiembre, día de la conmemoración de la Independencia de Brasil, atendiendo al gusto positivista ortodoxo por las fechas significativas de la nacionalidad. Sus dirigentes tomaron como patrono de la dependencia al pregonero de la aplicación de técnicas disciplinarias en la vida social brasileña, José Bonifácio de Andrada e Silva ${ }^{22}$. No es necesario describir la ceremonia o referirse al acta de inauguración o a discursos y otras piezas documentales bastante mencionadas por autores que, al referirse a la fundación del SPI, hicieron eco de la historia autoinstituida del Servicio, solidarizándose implícitamente con la defensa de la necesaria existencia de un único aparato de poder estatizado (y estatizante) para la acción frente a los indios. José Bonifácio es, sin duda, un excelente defensor de proyectos que pretendían la "modernización" nacional, siempre que éstos se

\footnotetext{
${ }^{21} \mathrm{El}$ sertanismo se refiere a la actividad realizada por los exploradores que se aventuraban en el interior del sertão. Durante el periodo colonial, ellos fueron los principales responsables de extender las fronteras del país.

22 José Bonifácio de Andrada e Silva (1763-1838) fue un naturalista, estadista y poeta brasileño. Es conocido por el epíteto de "Patriarca de la Independencia". Fue ministro del Reino y de los Negocios Extranjeros de enero de 1822 a julio de 1823 y, entre otras importantes acciones en la vida pública del periodo, tuvo un destacado paso por la Primera Asamblea Constituyente del Brasil independiente, después de ser tutor de Don Pedro II cuando Don Pedro I, su padre, dejó Brasil para regresar a Portugal. Fue uno de los primeros y más importantes pensadores de la construcción del Estado y de la nación en Brasil. Entre sus numerosos estudios, en los que abordó muchos temas, uno se volvería célebre en el campo de la acción indigenista, frecuentemente citado por los positivistas y seguidores de Rondon: Apuntes para la Civilización de los Indios Bravos del Imperio de Brasil, donde además de recomendar métodos "persuasivos" en el trato de los indios bravos, también les concedía un lugar en la nacionalidad por medio del mestizaje y del uso de su fuerza de trabajo.
}

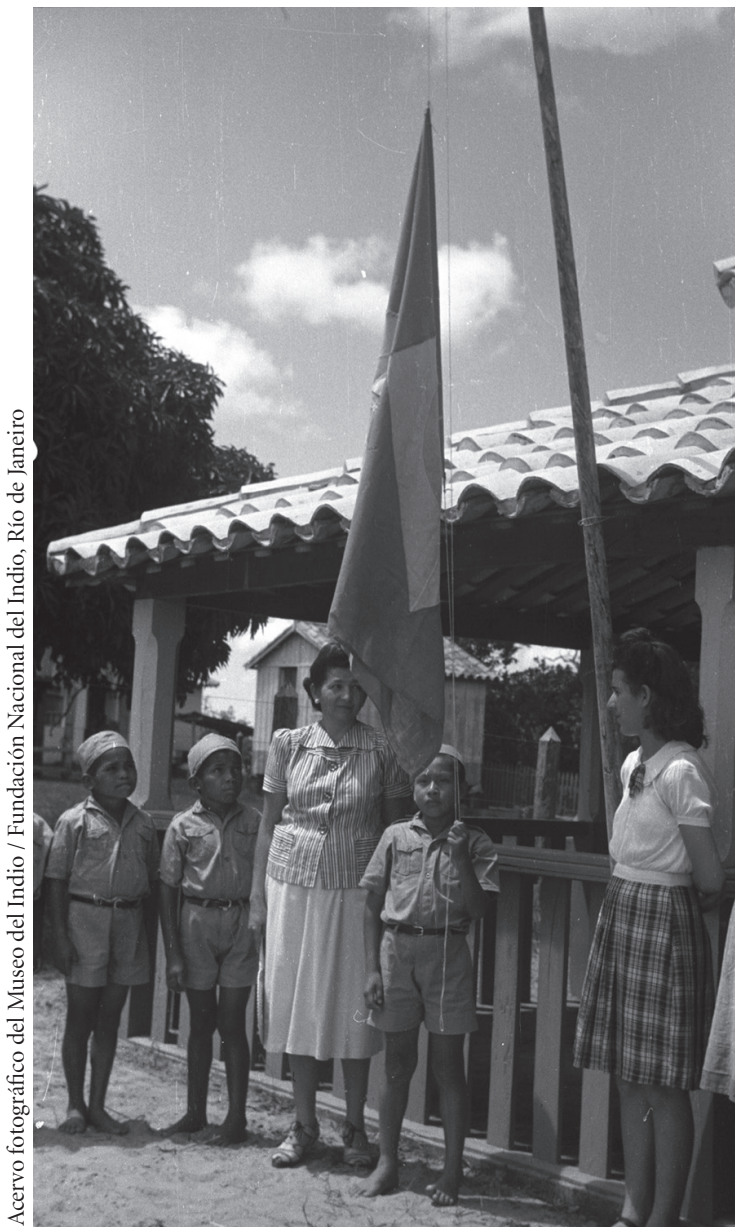

basaran en el mantenimiento de los límites jerarquizantes de participación política en la vida pública.

Pero es más importante reconstruir las clasificaciones y técnicas con que operó el Servicio, además de la morfología organizativa concebida y sus posibilidades de implementación. Para esto, los reglamentos emitidos por los decretos 8072 — del 20 de junio de 1910 — y 9214 — del 15 de diciembre de 1911—, por medio de los cuales se crea y reglamenta el SPILTN, son piezas importantes por lo que traducen del proyecto. El último fue fruto de la reforma ministerial de Rodolpho Miranda, adoptada en el citado decreto 8199 del 11 de agosto de 1911. En lapso transcurrido entre los dos, se inició la dispersión espacial del SPILTN con la implementación de unidades de acción 


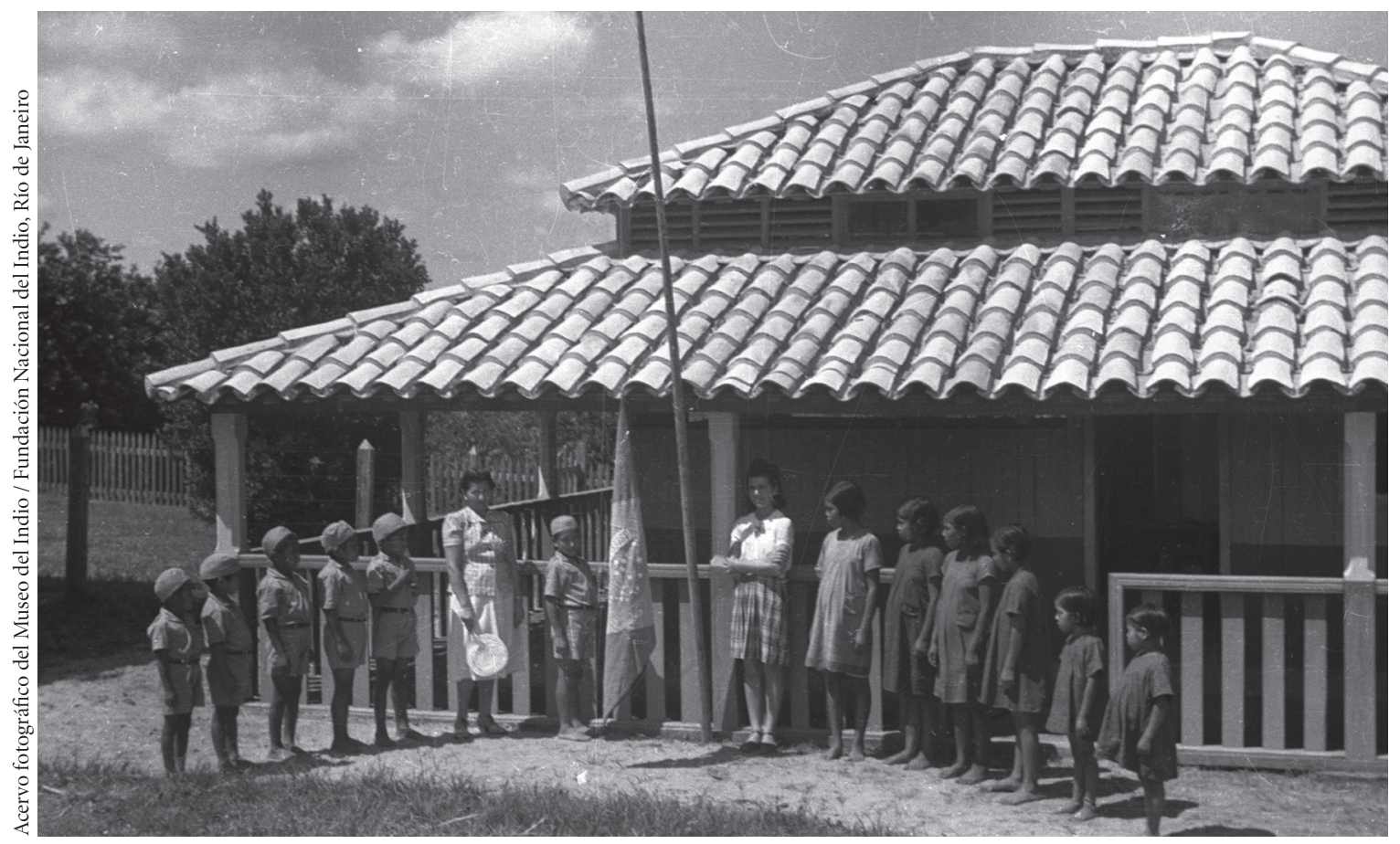

locales (puestos indigenas) y regionales (inspecciones regionales), y sucedieron dos hechos importantes para el desarrollo de la institución.

El primero tiene que ver con la formulación y el envío a Pedro Toledo, ministro de Agricultura, Industria y Comercio en 1912, del texto de ley que definiría un estatuto jurídico para la población nativa de Brasil —mejor dicho, que haría del término indios la designación de un estatus jurídico y la pieza central de un código-. El proyecto de ley fue concebido por Manoel Tavares da Costa Miranda y por el entonces primer teniente Alípio Bandeira (en esa época, jefe de la segunda subdirección del Servicio e inspector en el estado de Amazonas, respectivamente), ambos positivistas ortodoxos y correligionarios de Cândido Rondon. Dicho proyecto de ley fue turnado a la Cámara de Diputados en 1912. Las ideas allí expresadas ganarían la forma de ley bajo el ya mencionado artículo sexto del Código Civil y de la Ley 5484/28, dispositivo legal que le confirió la función de tutelar a los indios al ya entonces SPI.

El segundo fue la solicitud de retorno a los servicios del Ministerio de Guerra de los oficiales desplazados de la
Comisión Rondon al SPILTN, hecha por notificación del ministro de Guerra el 10 de noviembre de 1911, así como las reacciones que provocaría.

$\mathrm{Al}$ citar estos acontecimientos cabe destacar algunos elementos básicos en la constitución del Servicio, en buena parte referencias explícitas de su historia, "fantasmas" presentes en la formulación de los actuales textos legales, además de ser indiscutiblemente intrínsecos a las técnicas del gobierno aplicadas a los indios:

a) La necesidad de un código que ubique a los indígenas en un sistema de estratificación de derechos civiles y políticos predefinidos - fundamento legal de la acción administrativa estatizada—, como parte de la definición del orden jurídico-político inaugurado con el fin de la esclavitud en 1888 y de los cambios introducidos con el advenimiento de la República en 1889.

b) La lucha en torno a la permanencia de los militares en su papel de gestores del proceso de aplicación, explicitándose las solidaridades entre la protección a los indios y el control/construcción del territorio, además de las formas 
de violencia latente, oculta, pero siempre capaz de hacerse presente, horizonte de asimetría esencial para el mantenimiento de la conquista de espacios y poblaciones.

La forma en que fue pensado el estatus jurídico del indio - bajo el marco del evolucionismo presente en todos los matices de la imaginación política de finales del siglo XIX y principios del XX- puede ser leída como especificidad histórica de la relación entre la organización administrativa, el pueblo conquistador y el botín. De hecho y de derecho, tal estatus fue un instrumento en el proceso de integración de la población indígena a una comunidad política representada como nacional: el atributo de indianidad sería la vía de acceso y la forma intermedia del cumplimiento de un proyecto de extinción de los pueblos nativos como entidades discretas, dotadas de una historicidad diferencial y de autodeterminación política. En ese proyecto, lo que se pretendía era transformar a los indígenas en trabajadores rurales y no matarlos: se trataba de un dulce etnocidio y no de un cruento genocidio, como en realidad sucedía en el Brasil de aquellos tiempos. Hasta la fecha, las masacres de indígenas no son ajenas a la realidad brasileña.

Por otro lado, el hecho de que esta legislación dejaba al ejercicio cotidiano de las relaciones de poder, a través de la administración tutelar, la función de definir quién era (o sería) indio y quién no abría espacio a las interminables redes de clientelas que articularían - y hasta hoy articulan- el marco nacional de la administración indigenista. En estas redes, los propios pueblos nativos tienen un papel primordial, ocupando al menos un tercio de los efectivos de la Fundación Nacional del Indio. El clientelismo de Estado es un fenómeno muy denunciado y todavía poco conocido.

Por lo tanto, estudiar la historia de las políticas y de las ideologías indigenistas es estratégico para comprender la vida política de los Estados nacionales. Hacerlo es como excavar fósiles de los procesos de formación del Estado, fenómeno nada despreciable para el conocimiento sociohistórico. Tales ideas han encontrado resonancia y otras formulaciones en la obra de autores de estudios sobre el indigenismo y las políticas indigenistas de otros países. En este momento histórico, en que los indígenas se encuentran en las universidades apropiándose de conoci- mientos de gran importancia para revisar su pasado y pensar sus futuros posibles, es importante que tales perspectivas dialoguen, se difundan y, con ojos aliados a los pueblos indígenas y respetuosos de su autonomía, replanteen las acciones de los Estados nacionales frente a los pueblos autóctonos.

\section{Bibliografía}

Blanchette, Thaddeus Gregory, 2006, Cidadãos e selvagens: antropologia aplicada e administração indígena nos Estados Unidos, 1880, tesis de doctorado en Antropología Social, Programa de Posgrado en Antropología Social, Museo Nacional, Universidad Federal de Río de Janeiro, Río de Janeiro.

Carvalho, José Murilo de, 1990, A formação das almas: 0 imaginário da República no Brasil, Companhia das Letras, São Paulo.

1995, Desenvolvimiento de la ciudadanía en Brasil, Fondo de Cultura Económica, México.

Couto, Ione de Freitas, 2009, Armazém da Memória da Seção de Estudos do Serviço de Proteção aos Índios-SPI, tesis de doctorado en Memoria Social, Programa de Posgrado Memoria Social, Centro de Ciencias Humanas y Sociales, Universidad Federal de Río de Janeiro, Río de Janeiro.

Freire, Carlos Augusto da Rocha, 1990, Indigenismo e Antropologia. O Conselho Nacional de Proteção aos Índios na gestão Rondon (1939-1955), tesis de maestría en Antropología, Programa de Posgrado en Antropología Social, Museo Nacional, Universidad Federal de Río de Janeiro, Río de Janeiro.

—_, 2005, Sagas Sertanistas: práticas e representações do campo indigenista no século XX, tesis de doctorado en Antropología, Programa de Posgrado en Antropología Social, Museo Nacional, Universidad Federal de Río de Janeiro, Río de Janeiro.

Geertz, Clifford, 1991, Negara. O Estado teatro no século XIX, Difel/Bertrand, Lisboa y Río de Janeiro.

Gomes, Mercio Pereira, 2009, "Por que sou rondoniano", Estudos Avançados, vol. 23, núm. 65, pp. 173-191, enero-abril, São Paulo.

Mattos, André Luís Lópes Borges de, 2007, Darcy Ribeiro: uma trajetória (1944-1982), tesis de doctorado en Ciencias Sociales, Universidad Estatal de Campinas, Río de Janeiro.

Mendes, Marcos de Souza, 2006, Heinz Forthmann e Darcy Ribeiro: cinema documentário no Serviço de Proteção aos Índios (SPI), 1949-1959, tesis de doctorado en Multimedios, Universidad Estatal de Campinas, Río de Janeiro.

Mendonça, Sônia Regina de, 1997, O ruralismo brasileiro: 1888-1931, Hucitec, São Paulo.

Morales, Lúcia Arrais, 2002, Vai e Vem, Vira e Volta: As rotas dos soldados da borracha, Anna Blume, São Paulo. 
O’Reilly, Donald Francis, 1969, Rondon: Biography of a Brazilian Republican Army Commander, tesis de doctorado en Historia, University Microfilms Internacional, Ann Arbor.

$-\mathrm{y}$ Carlos Augusto da Rocha Freire, 2006, A presença indígena na história do Brasil, Trilhas de Conhecimentos/LACED, MEC/SECAD, UNESCO, Río de Janeiro/Brasilia (Colección Educación para Todos, Serie Vías de los Saberes, disponible en línea: <http://www.trilhasdeconhecimentos.etc.br/livros/arquivos/ColET13_Vias02WEB.pdf >).

Peirano, Mariza Gomes de Souza, 1981, The Anthropology of Anthropology: the Brazilian Case, tesis de doctorado en Antropología, Universidad de Harvard, Cambridge.

Ramos, Jair de Souza, 2006, O poder de domar do fraco: formação de autoridade e poder tutelar na política de povoamento do solo nacional, EDUFF, Niterói.

Ribeiro, Darcy, 1962, A politica indigenista brasileira, Servicio de Información Agrícola, Ministerio de Agricultura, Río de Janeiro.

— 1977 [1970], Os índios e a civilização: a integração dos indígenas no Brasil moderno, Editora Civilización Brasileña, Río de Janeiro.

Souza Lima, Antonio Carlos de, 1985a, Aos fetichistas, Ordeme Progresso: um estudo do campo indigenista no seu estado de formação, tesis de maestría en Antropología, Programa de Posgrado en Antropología Social, Museo Nacional, Univer-
Janeiro/Marco Zero, Río de Janeiro/São Paulo, pp. 149-204 (disponible en línea: <http://www.laced.etc.br/pdfs/ACSL0200.pdf $>$ ).

, 1989, "Os museus na história natural e a construção do indigenismo: notas para uma sociologia das relações entre campo intelectual e campo político no Brasil", Comunicação, núm. 13, Programa de Posgrado en Antropología Social, Museo Nacional, Universidad Federal de Río de Janeiro, (disponible en línea: <http://www.laced.etc.br/pdfs/ Comunicação\%20do\%20PPGAS\%20no13.pdf>).

, 1991, “O Santo Soldado, Pacificador, bandeirante, amansador de índios, civilizador dos sertões, apóstolo da humanidade. Uma leitura de Rondon conta sua vida de Esther de Viveiros", Comunicação, núm. 21, Programa de Posgrado en Antropología Social, Museo Nacional, Universidad Federal de Río de Janeiro (disponible en línea: <http://www. laced.etc.br/pdfs/Comunicações\%20PPGAS\%20no2021. pdf $>$ ).

- 1995, Um grande cerco de paz: Poder tutelar, indianidade e formação do Estado no Brasil, Vozes, Petrópolis.

—_, 2001, "Fundãçao Nacional do Índio", en Dicionário Histórico Biográfico Brasileiro, Fundación Getúlio Vargas, Río de Janeiro.

_ 2006 , "El indigenismo en Brasil: migración y reapropiaciones de un saber administrativo", en João Pacheco de Oliveira (comp.), Hacia una antropología del indigenismo, Contra Capa/Centro Amazónico de Antropología y Aplicación Práctica, Río de Janeiro/Lima, pp. 97-125.

Stauffer, David Hall, 1955, The Origin and Establishment of Brazil's Indian Service, 1889-1910, tesis de doctorado en Historia, Universidad de Texas, Austin.

Vianna, Adriana de Resende Barreto, 2007 [1999], El Mal que se Adivina-policía y minoridad en Río de Janeiro 1910-1920, ADHOC, Buenos Aires. 